\title{
The efficacy of perioperative gabapentin for the treatment of postoperative pain following total knee and hip arthroplasty: a meta-analysis
}

Jiayu Kang ${ }^{1,2,3}$, Zhihu Zhao ${ }^{2}$, Jianwei Lv' ${ }^{2}$ Lei Sun ${ }^{2,3}$, Bin Lu' ${ }^{2,3}$, Benchao Dong ${ }^{2,3}$, Jianxiong Ma ${ }^{2,3^{*}}$ and Xinlong $\mathrm{Ma}^{2,3,4^{*}}$

\begin{abstract}
Background: Postoperative pain after total knee arthroplasty (TKA) and total hip arthroplasty (THA) influence patients' rehabilitation and life quality. Although gabapentin has been widely used for analgesia, its efficacy is still controversial in TKA and THA. This meta-analysis was performed to assess the efficacy and safety of gabapentin following TKA and THA.
\end{abstract}

Method: Electronic databases including PubMed, EMBASE, Cochrane Central Register of Controlled Trials, MEDLINE, and ClinicalTrials.gov were comprehensively retrieved for randomized controlled trials from their inception to June 2019. A total of 7 studies, which compared the administration of gabapentin with that of placebo for the treatment of postoperative pain, were included in our meta-analysis. The meta-analysis was performed according to the Preferred Reporting Items for Systematic Reviews and Meta-Analyses (PRISMA) guidelines.

Result: There was no difference in pain score at $24(P=0.87), 48(P=0.15)$, and $72(P=0.85) \mathrm{h}$ associated with the use of gabapentin. Likewise, no difference in accumulative morphine consumption at $48 \mathrm{~h}$ following TKA or THA was found between gabapentin and placebo ( $\mathrm{DM}=-8.14,95 \% \mathrm{Cl}-18.55$ to $2.28, P=0.13)$. The incidence of opioid-related adverse effects, including nausea, pruritus, sedation, and dizziness, is no difference between gabapentin and placebo group. However, subgroup analysis indicated that gabapentin could reduce the incidence of pruritus after TKA (RR $=0.35,95 \% \mathrm{Cl} 0.12$ to $0.99, P=0.05)$.

Conclusion: Based on our meta-analysis, gabapentin did not decrease postoperative pain, cumulative morphine consumption, and the incidence of adverse effects after TKA and THA. There was not enough evidence to support the administrations of gabapentin for postoperative pain after TKA and THA.

\footnotetext{
*Correspondence: k534271338@126.com; 534271338@qq.com

${ }^{2}$ Tianjin Hospital, Tianjin University, Tianjin 300211, People's Republic of China

Full list of author information is available at the end of the article
}

(c) The Author(s). 2020 Open Access This article is licensed under a Creative Commons Attribution 4.0 International License, which permits use, sharing, adaptation, distribution and reproduction in any medium or format, as long as you give appropriate credit to the original author(s) and the source, provide a link to the Creative Commons licence, and indicate if changes were made. The images or other third party material in this article are included in the article's Creative Commons licence, unless indicated otherwise in a credit line to the material. If material is not included in the article's Creative Commons licence and your intended use is not permitted by statutory regulation or exceeds the permitted use, you will need to obtain permission directly from the copyright holder. To view a copy of this licence, visit http://creativecommons.org/licenses/by/4.0/ The Creative Commons Public Domain Dedication waiver (http://creativecommons.org/publicdomain/zero/1.0/) applies to the data made available in this article, unless otherwise stated in a credit line to the data. 


\section{Introduction}

Total knee arthroplasty (TKA) and total hip arthroplasty (THA) procedures are generally regarded as some of the most successful surgeries and provide significant benefit to patients with severe knee and hip functional impairment [1]. Recently, more than 370 thousand THA and 700 thousand TKA were operated in the USA with an increasing trend in the foreseeable future [2, 3]. However, about half of patients undergoing TKA and THA suffer from severe postoperative pain in spite of multimodal analgesia [4, 5]. Pain after total joint arthroplasty is the most common cause of prolonging length of hospital stay and functional recovery as well as a common reason for readmission [6]. Therefore, the management of pain after total joint arthroplasty has substantial benefits for the patient to achieve early functional recovery.

In recent decades, multimodal analgesia techniques including gabapentin have generally been used for pain control in order to reduce the side effects of morphine such as sedation, nausea, and vomiting [7]. Gabapentin has a molecular structure similar to that of the neurotransmitter $\gamma$-aminobutyric acid (GABA) and acts by inhibiting certain calcium channels, which can decrease the release of neurotransmitters so that it has an established role in the treatment of partial seizures as well as neuropathic pain conditions [8]. It has been indicated postoperatively for a variety of surgeries including TKA and THA to reduce postoperative pain and opioid consumption [9].

In the last few years, some randomized controlled trials (RCTs) have been conducted to determine the efficacy of perioperative gabapentin in the management of postoperative pain in patients undergoing TKA or THA [10-12]. However, the opposite conclusions have been reached. Several previous metaanalyses supported the use of gabapentin after THA or TKA, while Hamilton et al. [13] showed that no evidence to support the routine use of gabapentinoids in pain control following TKA. Therefore, the aim of this current meta-analysis was to investigate the effect of the gabapentin in the management of postoperative pain and the risk of drug-related adverse effects following TKA and THA.

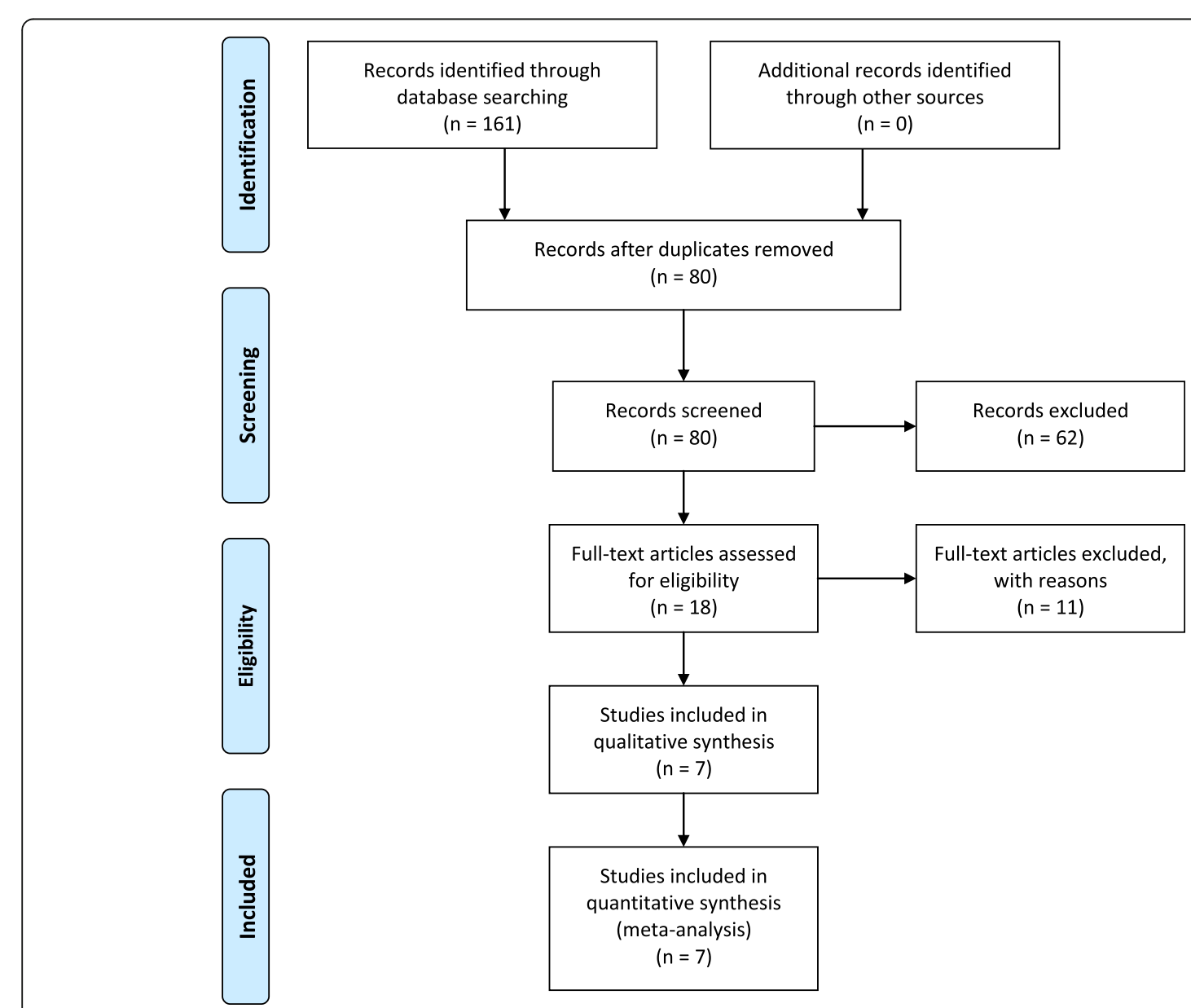

Fig. 1 Search result and the selection procedure 


\section{Materials and methods Search strategy}

This meta-analysis is reported in accordance with the Preferred Reporting Items for Systematic Reviews and MetaAnalyses (PRISMA) statement. Electronic databases including PubMed, EMBASE, Cochrane Central Register of Controlled Trials, MEDLINE, and ClinicalTrials.gov were retrieved for randomized controlled trials (RCTs), cohort studies, and controlled clinical trials (CCTs) from their inception to June 15, 2019. The following medical subject heading terms, keywords, and their combinations were used: "postoperative pain, total hip arthroplasty, total knee arthroplasty, total hip replacement, total knee replacement and gabapentin". No restrictions were imposed on language or geographic location.

\section{Inclusion and exclusion criteria}

Studies were regarded as eligible for inclusion if they satisfied the following criteria. Population: patients undergoing TKA or THA. Intervention: gabapentin for postoperative pain control. Comparison: placebo or nothing controlled multimodal analgesia method. Outcomes: visual analog scale (VAS) at 24, 48 , and $72 \mathrm{~h}$, cumulative morphine consumption ( 0 to $48 \mathrm{~h}$ ), and adverse events (sedation, nausea, pruritus, and dizziness). Study design: RCTs, CCTs, and cohort studies.

\section{Study selection and data extraction}

Two independent investigators excluded studies depending on titles and abstracts, and studies that met the inclusion criteria were searched for full-text assessment. Disagreements were resolved by a third reviewer. The following data were extracted from the eligible literature by two investigators independently: first author's name, publication year, sample size, gabapentin dose and regimen, anesthetic techniques, pain scores, morphine consumption, knee flexion degree, and side effects (nausea, sedation, dizziness, and pruritus). The primary outcome is VAS score with activity at $48 \mathrm{~h}$. Pain at rest was used instead if pain with activity was not reported. The secondary outcome contained VAS score at 24 and $72 \mathrm{~h}$, cumulative morphine consumption at $48 \mathrm{~h}$, and adverse events (sedation, nausea, pruritus, and dizziness). All cumulative morphine consumption was converted to oral morphine equivalent dose.

\section{Quality assessment}

Two reviewers used the criteria outlined in the Cochrane Handbook for Systematic Reviews of Interventions to evaluate the risk of bias in each included study. Disagreements were resolved by consensus. Seven domains related to risk of bias were evaluated in each eligible study as follows: (1) random sequence generation,

Table 1 Description of included studies

\begin{tabular}{|c|c|c|c|c|c|c|c|}
\hline Study & Country & Anesthesia & $\begin{array}{l}\text { Surgical } \\
\text { approach }\end{array}$ & $\begin{array}{l}\text { No. of patients } \\
\text { control group }\end{array}$ & $\begin{array}{l}\text { No. of patients } \\
\text { gabapentin group }\end{array}$ & Gabapentin intervention & $\begin{array}{l}\text { Concomitant pain } \\
\text { management }\end{array}$ \\
\hline \multirow[t]{4}{*}{$\begin{array}{l}\text { Clarke } \\
(2009)\end{array}$} & \multirow[t]{4}{*}{ Canada } & \multirow[t]{4}{*}{$\begin{array}{l}\text { Spinal } \\
\text { anesthesia }\end{array}$} & \multirow[t]{4}{*}{ TKA } & \multirow[t]{4}{*}{7} & 7 & Gabapentin 600 mg 2 h preoperatively. & \multirow[t]{4}{*}{$\begin{array}{l}\text { PCA with } \\
\text { morphine }\end{array}$} \\
\hline & & & & & 8 & $\begin{array}{l}\text { Gabapentin } 600 \text { mg } 2 \mathrm{~h} \text { preoperatively and } 100 \\
\text { mg } 3 \text { times a day for } 4 \text { days postoperatively. }\end{array}$ & \\
\hline & & & & & 7 & $\begin{array}{l}\text { Gabapentin } 600 \text { mg } 2 \text { h preoperatively and } 200 \\
\text { mg } 3 \text { times a day for } 4 \text { days postoperatively. }\end{array}$ & \\
\hline & & & & & 7 & $\begin{array}{l}\text { Gabapentin } 600 \text { mg } 2 \mathrm{~h} \text { preoperatively and } 300 \\
\text { mg } 3 \text { times a day for } 4 \text { days postoperatively. }\end{array}$ & \\
\hline $\begin{array}{l}\text { Texas } \\
(2012)\end{array}$ & America & Unclear & TKA & 17 & 20 & $\begin{array}{l}\text { Gabapentin } 600 \mathrm{mg} \text { preoperatively and } 300 \mathrm{mg} \\
\text { per } 8 \mathrm{~h} \text { for } 3 \text { days postoperatively. }\end{array}$ & Unclear \\
\hline $\begin{array}{l}\text { Paul } \\
(2013)\end{array}$ & Canada & $\begin{array}{l}\text { Spinal } \\
\text { anesthesia }\end{array}$ & TKA & 49 & 52 & $\begin{array}{l}\text { Gabapentin } 600 \text { mg } 2 \text { h preoperatively and } 200 \\
\text { mg } 3 \text { times a day for } 2 \text { days postoperatively. }\end{array}$ & $\begin{array}{l}\text { PCA with } \\
\text { morphine }\end{array}$ \\
\hline $\begin{array}{l}\text { Clarke } \\
(2014)\end{array}$ & Canada & $\begin{array}{l}\text { Spinal } \\
\text { anesthesia }\end{array}$ & TKA & 76 & 79 & $\begin{array}{l}\text { Gabapentin } 600 \text { mg } 2 \mathrm{~h} \text { preoperatively and } 200 \\
\text { mg } 3 \text { times a day for } 4 \text { days postoperatively. }\end{array}$ & $\begin{array}{l}\text { PCA with } \\
\text { morphine }\end{array}$ \\
\hline \multirow[t]{2}{*}{$\begin{array}{l}\text { Lunn } \\
\text { (2015) }\end{array}$} & \multirow[t]{2}{*}{ Denmark } & \multirow[t]{2}{*}{$\begin{array}{l}\text { Spinal } \\
\text { anesthesia }\end{array}$} & \multirow[t]{2}{*}{ TKA } & \multirow[t]{2}{*}{99} & 100 & $\begin{array}{l}\text { Gabapentin } 900 \text { mg } 2 \text { h preoperatively and } 600 \\
\text { mg morning, } 300 \text { mg night for } 7 \text { days. }\end{array}$ & \multirow[t]{2}{*}{$\begin{array}{l}\text { PCA with } \\
\text { morphine }\end{array}$} \\
\hline & & & & & 99 & $\begin{array}{l}\text { Gabapentin } 1300 \mathrm{mg} 2 \mathrm{~h} \text { preoperatively and } 900 \\
\text { mg morning, } 400 \mathrm{mg} \text { night for } 7 \text { days } \\
\text { postoperatively. }\end{array}$ & \\
\hline \multirow[t]{2}{*}{$\begin{array}{l}\text { Clarke } \\
(2009)\end{array}$} & \multirow[t]{2}{*}{ Canada } & \multirow[t]{2}{*}{$\begin{array}{l}\text { Spinal } \\
\text { anesthesia }\end{array}$} & \multirow[t]{2}{*}{ THA } & \multirow[t]{2}{*}{39} & 40 & Gabapentin 600 mg 2 h preoperatively & \multirow[t]{2}{*}{$\begin{array}{l}\text { PCA with } \\
\text { morphine }\end{array}$} \\
\hline & & & & & 38 & Gabapentin 600 mg 2 h postoperatively & \\
\hline $\begin{array}{l}\text { Paul } \\
(2015)\end{array}$ & Canada & $\begin{array}{l}\text { Spinal } \\
\text { anesthesia }\end{array}$ & THA & 54 & 48 & $\begin{array}{l}\text { Gabapentin } 600 \text { mg } 2 \text { h preoperatively and } 200 \\
\text { mg } 3 \text { times for } 2 \text { days postoperatively. }\end{array}$ & $\begin{array}{l}\text { PCA with } \\
\text { morphine }\end{array}$ \\
\hline
\end{tabular}




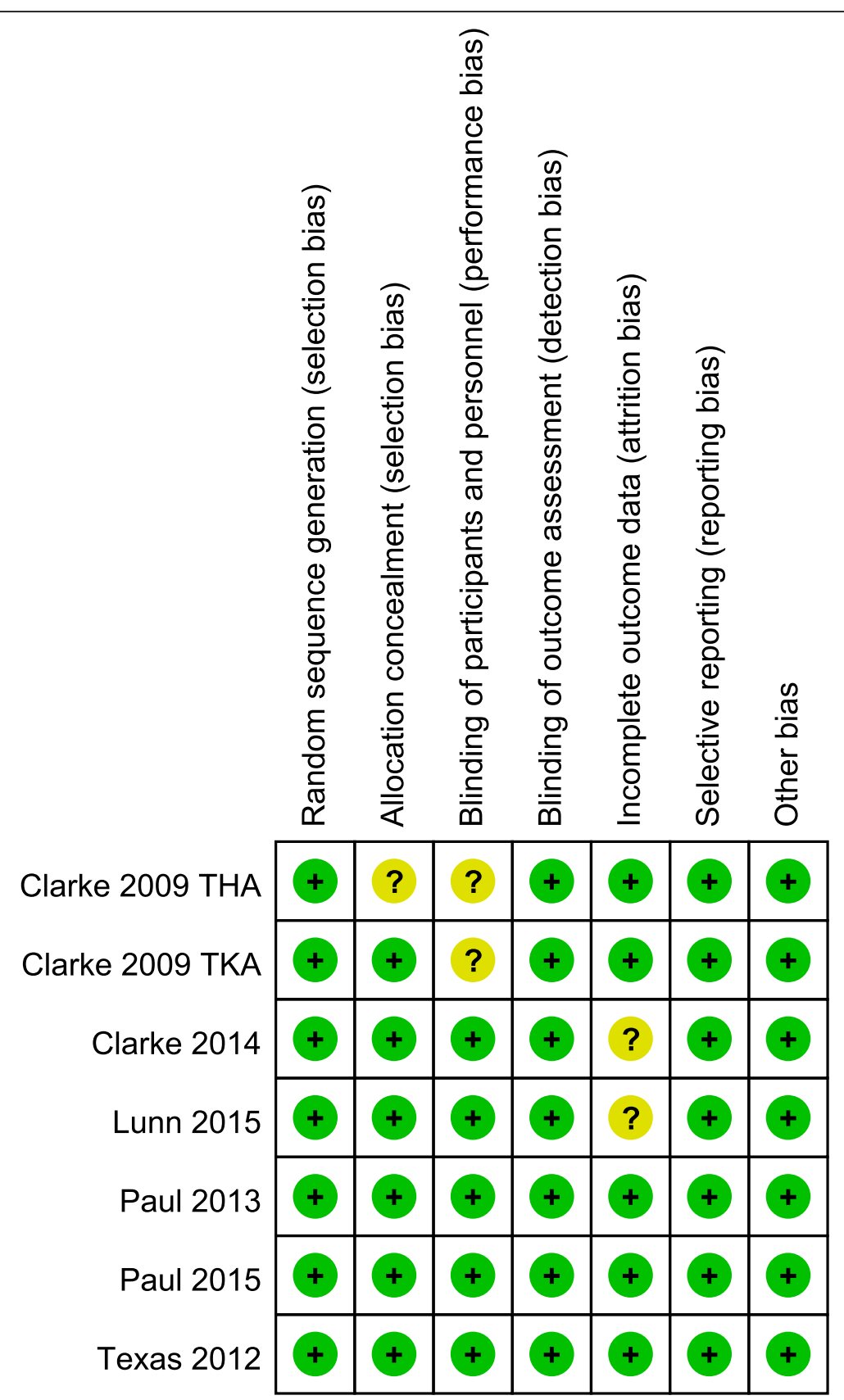

Fig. 2 Assessment of risk of bias of included studies

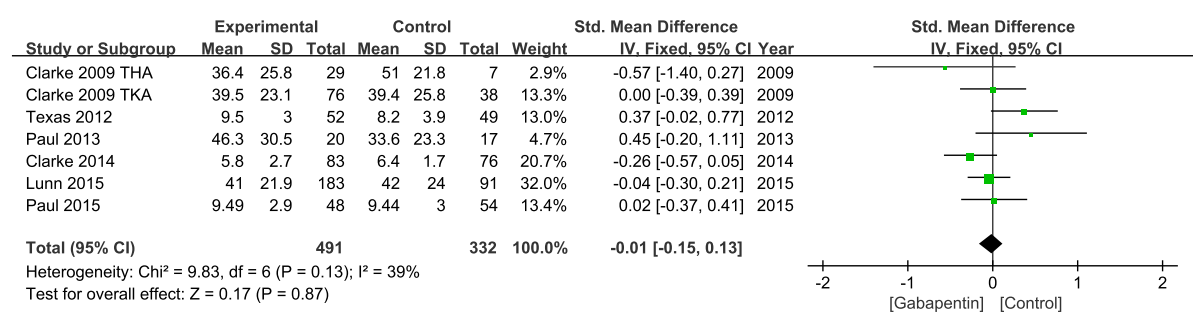

Fig. 3 VAS score at $24 \mathrm{~h}$ after TKA or THA. VAS, visual analog scale; TKA, total knee arthroplasty; THA, total hip arthroplasty 


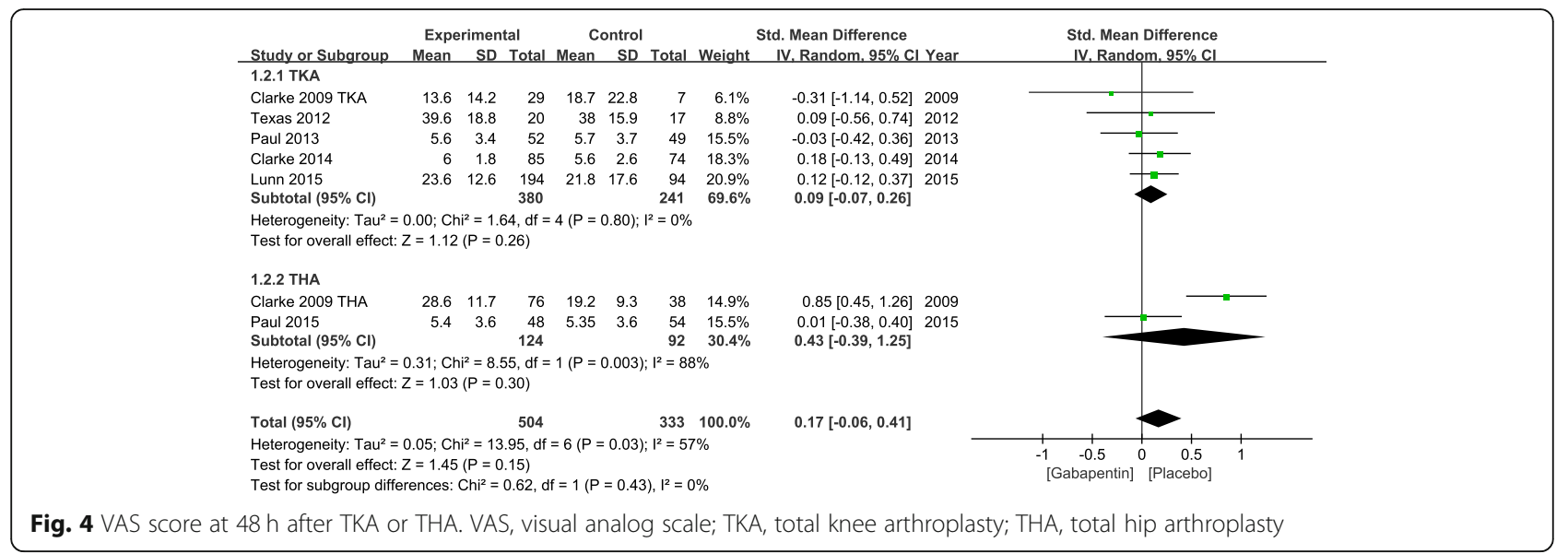

(2) allocation concealment, (3) blinding of participants and personnel, (4) blinding of outcome assessment, (5) incomplete outcome data, (6) selective reporting, and (7) other bias. The level of the risk of bias was categorized as "low risk," "high risk," or "unclear risk."

\section{Statistical analysis}

Data analysis was performed using the Review Manager Software for Windows (RevMan Version 5.3, Copenhagen; The Nordic Cochrane Center, The Cochrane Collaboration, 2014). For continuous data, the standardized mean difference with $95 \%$ confidence interval $(95 \% \mathrm{CI})$ was calculated. The cumulative morphine consumption was assessed by the mean difference with a 95\% CI. Dichotomous data were expressed as the risk ratio indicates the effect of intervention. Statistical heterogeneity of data was evaluated using the $I^{2}$ value and chi-squared test. If $I^{2}>$ $50 \%$ and $P<0.05$, statistical was considered to be heterogeneous, and the random effects model was used. Otherwise, the fixed effects model was performed for metaanalysis.

\section{Results}

\section{Search results}

A total of 161 relevant studies were retrieved depending on search strategy, and no additional records were found during manual searches of references. Eightyone studies were removed as duplicate.
After assessing the titles and abstracts of the remaining 80 articles, 62 studies were removed as uncorrelated. Eleven studies were excluded according to the inclusion criteria through reading the full text. During selection, 4 studies were excluded because no subgroup of patients with placebo was analyzed. Seven studies were excluded because patients received a combination of gabapentin and other medicine. Finally, seven randomized controlled trials compared the use of gabapentin after TKA (5 studies) or THA (2 studies) with that of placebo or no treatment (Fig. 1) [14-20]. A total of 837 patients were included in this meta-analysis, and the characteristics are presented in Table 1. Six hundred twenty-one patients of five studies were for TKA, while 216 patients of another two studies were for THA. The 7 trials were published between 2009 and 2019. All 7 studies were RCTs, and one study was retrieved in ClinicalTrials.gov (NCT01680549) [20]. Seven studies compared gabapentin with placebo on postoperative pain according to VAS scale. Six studies reported cumulative morphine consumption at $48 \mathrm{~h}$. Four studies and three analyzed the incidence of drug-related adverse effects (sedation and nausea) respectively.

\section{Quality assessment}

The quality of RCTs is outlined in Fig. 2. Clarke et al. [14] did not describe the details of allocation

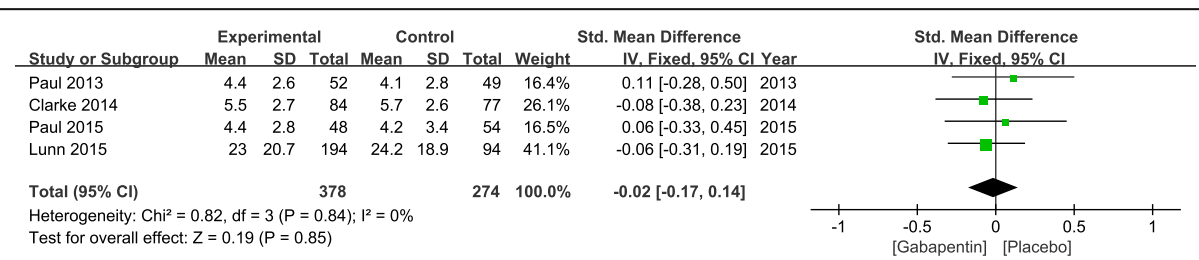

Fig. 5 VAS score at $72 \mathrm{~h}$ after TKA or THA. VAS, visual analog scale; TKA, total knee arthroplasty; THA, total hip arthroplasty 


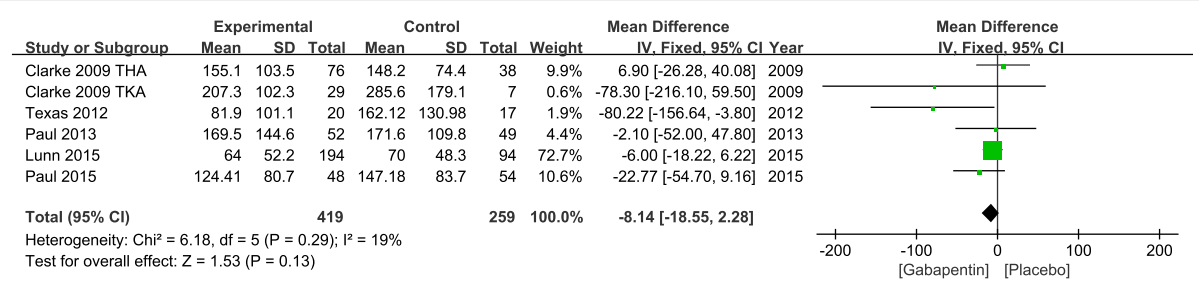

Fig. 6 Cumulative morphine consumption (0 to 48 h) after TKA or THA. TKA, total knee arthroplasty; THA, total hip arthroplasty

concealment, blinding of participants and personnel, presenting an unclear risk of bias. Clarke et al. [16] and Clarke et al. [18] did not report the method of blinding of outcome assessment and incomplete outcome data respectively, which presented an unclear risk of bias. A sensitivity analysis was performed according to the risk of bias, and exclusion of studies with high risk of bias did not influence the results.

\section{Meta-analysis result \\ VAS score at $24 h$}

At $24 \mathrm{~h}$, a total of 7 studies with 823 patients evaluated the VAS score. There was no significant heterogeneity in VAS score at $24 \mathrm{~h}\left(\chi^{2}=9.83, \mathrm{df}=6, I^{2}=39 \%, P=0.13\right)$ (Fig. 3). Therefore, a fixed effects model was used. Pooled results indicated that compared with placebo, no difference was seen in patients receiving gabapentin (standardized mean difference, - 0.01 [- 0.15, 0.13]; $P=0.87$ ) (Fig. 3).

\section{VAS score at $48 \mathrm{~h}$}

Data from 7 studies including 837 patients evaluated the postoperative pain regarding the VAS score at $48 \mathrm{~h}$. High heterogeneity limited analysis $\left(\chi^{2}=13.95, \mathrm{df}=6, P=\right.$ 0.03, $\left.I^{2}=57 \%\right)$. Hence, a random effects model was used, and a subgroup analysis was performed for the VAS score at $48 \mathrm{~h}$. Compared with placebo, gabapentin could not significantly reduce the postoperative pain after TKA and THA at $48 \mathrm{~h}(\mathrm{SMD}=0.17,95 \% \mathrm{CI}-0.06$ to $0.41, P=0.15$ ) (Fig. 4).

\section{VAS score at $72 \mathrm{~h}$}

Only 4 studies with 652 patients reported the postoperative pain according to the VAS score at $72 \mathrm{~h}$. There was no significant heterogeneity $\left(\chi^{2}=0.82\right.$, df $=3, P=0.84$, $I^{2}=0 \%$ ), and a fixed effects model was adopted. No significant difference was found between the gabapentin groups and placebo groups $(\mathrm{SMD}=-0.02,95 \% \mathrm{CI}-$ 0.17 to $0.14, P=0.85$ ) (Fig. 5).

\section{Cumulative morphine consumption}

A total of 678 patients from 6 studies were calculated the cumulative morphine consumption at $48 \mathrm{~h}$. We used a fixed effects model due to the low heterogeneity $\left(\chi^{2}=6.18\right.$, $\left.\mathrm{df}=5, P=0.29, I^{2}=19 \%\right)$. The outcome indicated that gabapentin could not significantly decrease the cumulative morphine consumption at $48 \mathrm{~h}$ compared with placebo $(\mathrm{DM}=-8.14,95 \% \mathrm{CI}-18.55$ to $2.28, P=0.13)$ (Fig. 6).

\section{Adverse effects}

Four studies reported the incidence rate of sedation. Due to the low heterogeneity $\left(\chi^{2}=1.18, \mathrm{df}=3, P=0.76\right.$, $I^{2}=0 \%$ ), a fixed effects model was used. No significant increase in the risk of sedation was found in patients who received gabapentin $(\mathrm{RR}=1.05,95 \% \mathrm{CI} 0.85$ to 1.28, $P=0.63$ ) (Fig. 7).

A total of 287 patients from 5 studies were evaluated the incidence rate of nausea. With no significant heterogeneity, a fixed effects model was adopted $\left(\chi^{2}=1.3 \mathrm{df}=\right.$ $\left.4, P=0.86, I^{2}=0 \%\right)$. No significant difference in the incidence of nausea was shown between gabapentin group and placebo $(\mathrm{RR}=0.86,95 \% \mathrm{CI} 0.72$ to $1.02, P=0.08$ ) (Fig. 8).

The incidence of pruritus was reported in five studies. High heterogeneity influenced the reliability of analysis $\left(\chi^{2}=17.06, \mathrm{df}=4, P=0.02, I^{2}=77 \%\right)$. Therefore, a random effects model was used. Although no difference was found in total group (RR $=0.56,95 \%$ CI 0.30 to $1.01, P$

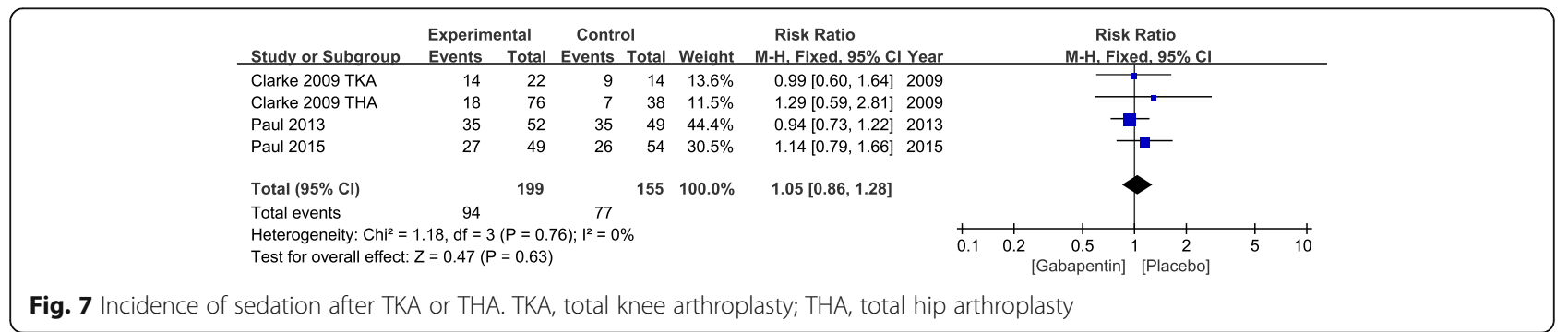




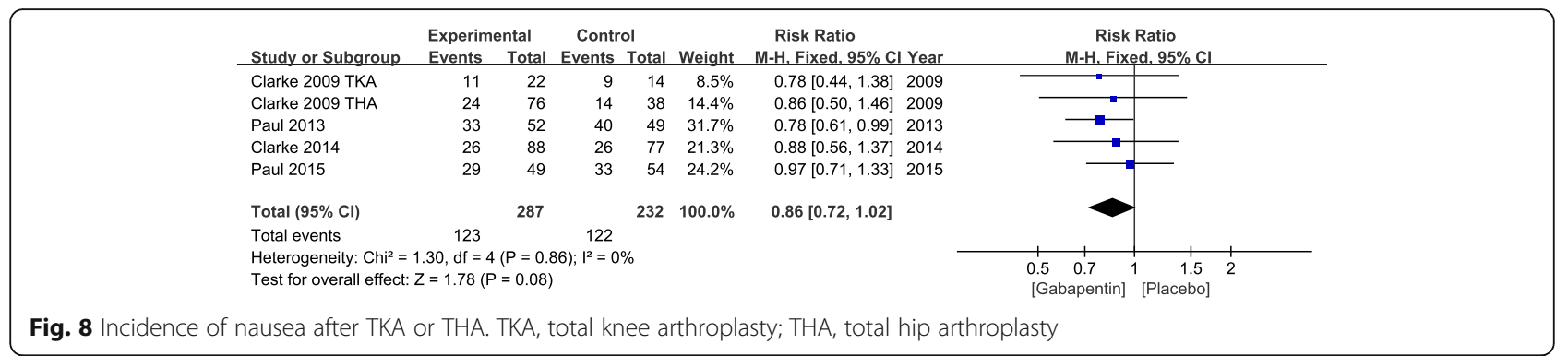

$=0.06$ ), subgroup analysis revealed that gabapentin could reduce the incidence of pruritus following TKA (RR $=0.35,95 \%$ CI 0.12 to $0.99, P=0.05$ ) (Fig. 9).

Data from five studies including 504 patients assessed the incidence rate of dizziness. With a significant heterogeneity, a random effects model was adopted $\left(\chi^{2}=9.5\right.$, $\left.\mathrm{df}=4, P=0.05, I^{2}=58 \%\right)$. No difference in the incidence of dizziness was detected in gabapentin group (RR $=0.75,95 \% \mathrm{CI} 0.47$ to $1.17, P=0.2$ ) (Fig. 10).

\section{Discussion}

The present meta-analysis was performed to evaluate the effect of gabapentin as a treatment of postoperative pain after TKA or THA. The results indicated that the use of gabapentin is not associated with reducing pain score at 24,48 , and $72 \mathrm{~h}$. There also was no significant difference between gabapentin group and placebo group in the total morphine consumption at $48 \mathrm{~h}$. Compared with control group, gabapentin did not significantly influence the incidence of opioid-related adverse effects, including nausea, sedation, and dizziness. Subgroup analysis indicated that gabapentin is associated with a reduction in the incidence of pruritus ( $R R=0.35,95 \% \mathrm{CI}$ 0.12 to $0.99, P=0.05)$ in TKA but no relevance in THA. The pooled results show no evidence to support the routine use of gabapentin in postoperative pain control after total knee arthroplasty or total hip arthroplasty.

The VAS as a common and effective indicator for pain rating was applied to assess the pain level for patients undergoing THA or TKA (0-100 or $0-10,0$ was no pain and 10 or 100 was unbearable pain) [21]. In our metaanalysis, we chose 24,48 , and $72 \mathrm{~h}$ as the point-in-time to evaluate the postoperative pain. However, the conclusions of this meta-analysis are contrary to several previous systematic studies evaluating the use of gabapentin for post-surgical pain in several different surgeries, such as cesarean, breast cancer surgery, and spinal surgery [22-25]. The reason for these contradictions may be the different mechanisms and response to pain at different surgical sites [13]. Mishriky et al. [26] reported that there was a significant correlation between types of surgery and postoperative pain scores.

In recent years, some studies share the same views with our meta-analysis on the effect of gabapentin in the management of postoperative pain after surgeries. Erkılıc et al. [27] found that gabapentin reduced IL-6 production on the first $24 \mathrm{~h}$, but the VAS scores at $24 \mathrm{~h}$ were not significant difference between gabapentin group and placebo group. No significant difference was found in VAS scores at $12,24,48$, and $72 \mathrm{~h}$ in another metaanalysis [13]. Thus, this meta-analysis indicated that

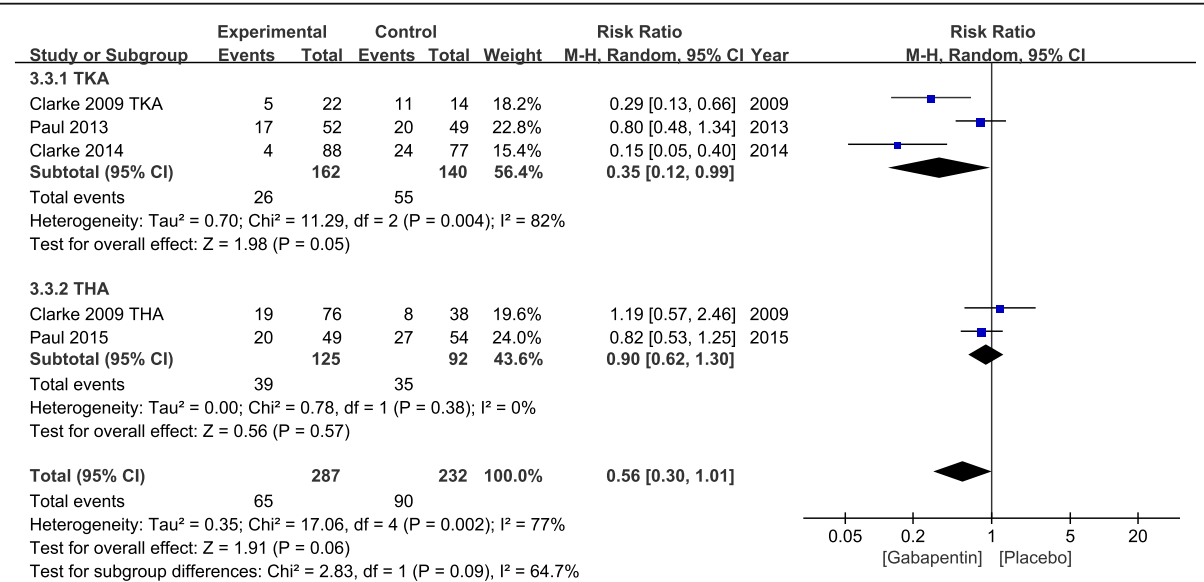

Fig. 9 Incidence of pruritus after TKA or THA. TKA, total knee arthroplasty; THA, total hip arthroplasty 


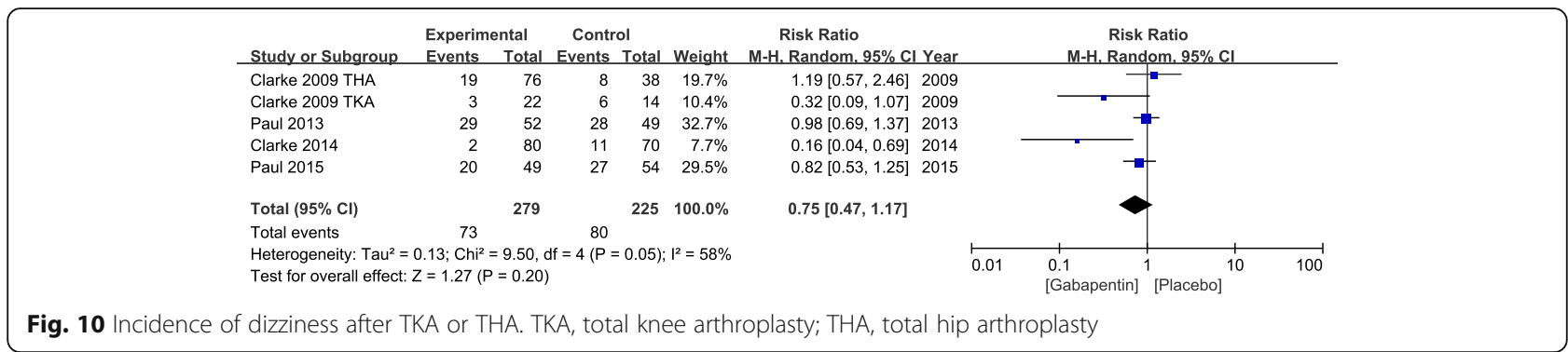

gabapentin cannot significantly reduce the acute pain following TKA or THA.

Although the present study indicated that gabapentin reduced the total morphine consumption by $8.14 \mathrm{mg}$ in the oral morphine equivalent dose at $48 \mathrm{~h}$ after TKA or THA, the reduction was not significant. This result of our study is contradictory to previous studies [11, 12]. Possible explanations may be the difference of the surgical procedure and the limitation sample sizes. However, Felder's [28] meta-analysis shared the same conclusion that no significant differences were found in the use of additional pain medications, supplemental opioids between gabapentin group and placebo group. Subgroup analysis showed that a reduction in the incident rate of postoperative pruritus after TKA was related to gabapentin, but the effect was not found after THA. Furthermore, the risk of other adverse effects including sedation, nausea, or dizziness was not significantly decreased in use of gabapentin, which proved that the reduction in total morphine consumption may not be of clinical relevance.

There are some limitations in our meta-analysis. Only 7 RCTs were included, and the small sample sizes limit the statistical efficacy of our meta-analysis. In addition, variety of study designs and analytical methods may lead to high heterogeneity in included studies. Other factors of included studies including anesthesia methods, way of incision, duration of surgery, and different implants could influence postoperative pain evaluation. Spinal anesthesia was used in 6 of all the 7 studies. It is unclear whether different anesthesia would affect the analgesic effect of gabapentin after TKA or THA. We did not assess TKA or THA postoperative recovery results because of lack of postoperative functional recovery data. Kjaer Petersen et al. [29] reported that the pain or psychological state 3-4years after TKA are not changed by pre- and perioperative administrations of gabapentin. In our meta-analysis, all included studies did not report long-term follow-up. Furthermore, the dosages and administration time of gabapentin were different in eligible studies. $\mathrm{Hu}$ et al. [30] indicated that there was a doseresponse relationship in total opioid consumption and postoperative pain for preoperative gabapentin.
Therefore, future studies are needed to determine the effect of gabapentin in TKA or THA.

\section{Conclusion}

Based on our meta-analysis, gabapentin did not reduce postoperative VAS scores at 24,48 , and $72 \mathrm{~h}$ and postoperative cumulative morphine consumption at $48 \mathrm{~h}$ after TKA and THA. Additionally, perioperative administrations of gabapentin did not influence the incidence of opioid-related adverse effects including sedation, pruritus, dizziness, and nausea following TKA or THA. In summary, our meta-analysis indicated that current evidence did not support the routine administrations of gabapentin in postoperative pain control after total hip arthroplasty and total knee arthroplasty. However, further high-quality and large randomized controlled trials are still required to be verified.

\section{Abbreviations \\ Cl: Confidence intervals; MD: Mean difference; THA: Total hip arthroplasty; \\ TKA: Total knee arthroplasty; VAS: Visual analog scale; RCTs: Randomized controlled trials; RR: Relative risk; CCTs: Controlled clinical trials; PRIS MA: Preferred Reporting Items for Systematic Reviews and Meta-Analyses}

\section{Acknowledgements}

No declaration.

\section{Authors' contributions}

All authors listed have made contributions to the meta-analysis. Jiayu Kang designed the study. Jiayu Kang, Zhihu Zhao, and Jianxiong Ma participated in performing the review and collecting the data. Jiayu Kang, Jianwei Lv, and Lei Sun took part in analyzing the data. Jianyu Kang, Bin Lu, and Benchao Dong wrote and revised the manuscript. All authors read and approved the final manuscript.

\section{Funding}

The National Natural Sciences Foundation of China [grant numbers 81572154, 81871777, 11772226].

Availability of data and materials

All data and materials were presented in the main paper.

Ethics approval and consent to participate

Not applicable.

Consent for publication

All authors have read the manuscript and given consent for publication.

Competing interests

No. 


\section{Author details}

'Department of Orthopedics, Jinhua Municipal Central Hospital, Jinhua, Zhejiang Province, People's Republic of China. ${ }^{2}$ Tianjin Hospital, Tianjin University, Tianjin 300211, People's Republic of China. ${ }^{3}$ Biomechanics Labs of Orthopaedics Institute, Tianjin Hospital, Tianjin, People's Republic of China. ${ }^{4}$ Department of Orthopedics, Tianjin Hospital, No. 155, Munan Road, Hexi District, Tianjin City, People's Republic of China.

Received: 6 January 2020 Accepted: 30 July 2020

Published online: 15 August 2020

\section{References}

1. Ferguson RJ, Palmer AJR, Taylor A, Porter ML, Malchau H, Glyn-Jones S. Hip replacement. Lancet. 2018;392(10158):1662-71.

2. Kurtz S, Ong K, Lau E, Mowat F, Halpern M. Projections of primary and revision hip and knee arthroplasty in the United States from 2005 to 2030. J Bone Joint Surg Am. 2007;89(4):780-5.

3. Bashinskaya B, Zimmerman RM, Walcott BP, Antoci V. Arthroplasty utilization in the United States is predicted by age-specific population groups. ISRN Orthop. 2012;2012:185938.

4. Chan EY, Blyth FM, Cheow SL, Fransen M. Postoperative pain following hospital discharge after knee replacement surgery: a patient survey. Pain Manag. 2013;3(3):177-88

5. Dimitriou D, Antoniadis A, Flury A, Liebhauser M, Helmy N. Total hip arthroplasty improves the quality-adjusted life years in patients who exceeded the estimated life expectancy. J Arthroplasty. 2018:33(11):3484-9.

6. Husted H, Lunn TH, Troelsen A, Gaarn-Larsen L, Kristensen BB, Kehlet H. Why still in hospital after fast-track hip and knee arthroplasty? Acta Orthop. 2011; 82(6):679-84.

7. Ranawat AS, Ranawat CS. Pain management and accelerated rehabilitation for total hip and total knee arthroplasty. J Arthroplasty. 2007;22(7 Suppl 3):12-5.

8. Calandre EP, Rico-Villademoros F, Slim M. Alphadelta ligands, gabapentin, pregabalin and mirogabalin: a review of their clinical pharmacology and therapeutic use. Expert Rev Neurother. 2016;16(11):1263-77.

9. Peng PW, Wijeysundera DN, Li CC. Use of gabapentin for perioperative pain control -- a meta-analysis. Pain Res Manag. 2007;12(2):85-92.

10. Han C, Li XD, Jiang HQ, Ma JX, Ma XL. The use of gabapentin in the management of postoperative pain after total hip arthroplasty: a metaanalysis of randomised controlled trials. J Orthop Surg Res. 2016;11(1):79.

11. Zhai L, Song Z, Liu K. The effect of gabapentin on acute postoperative pain in patients undergoing total knee arthroplasty: a meta-analysis. Medicine (Baltimore). 2016;95(20):e3673.

12. Han $C, L i X D$, Jiang $H Q, M a J X, M a X L$. The use of gabapentin in the management of postoperative pain after total knee arthroplasty: a PRISMAcompliant meta-analysis of randomized controlled trials. Medicine (Baltimore). 2016;95(23):e3883.

13. Hamilton TW, Strickland LH, Pandit HG. A meta-analysis on the use of gabapentinoids for the treatment of acute postoperative pain following total knee arthroplasty. J Bone Joint Surg Am. 2016;98(16):1340-50.

14. Clarke H, Pereira S, Kennedy D, Andrion J, Mitsakakis N, Gollish J, et al. Adding gabapentin to a multimodal regimen does not reduce acute pain, opioid consumption or chronic pain after total hip arthroplasty. Acta Anaesthesiol Scand. 2009:53(8):1073-83.

15. Paul JE, Nantha-Aree M, Buckley N, Shahzad U, Cheng J, Thabane L, et al. Randomized controlled trial of gabapentin as an adjunct to perioperative analgesia in total hip arthroplasty patients. Can J Anaesth. 2015;62(5):476-84.

16. Clarke H, Pereira S, Kennedy D, Gilron I, Katz J, Gollish J, et al. Gabapentin decreases morphine consumption and improves functional recovery following total knee arthroplasty. Pain Res Manag. 2009;14(3):217-22.

17. Paul JE, Nantha-Aree M, Buckley N, Cheng J, Thabane L, Tidy A, et al. Gabapentin does not improve multimodal analgesia outcomes for total knee arthroplasty: a randomized controlled trial. Can J Anesth. 2013;60(5): 423-31.

18. Clarke HA, Katz J, McCartney CJL, Stratford P, Kennedy D, Pagé MG, et al. Perioperative gabapentin reduces $24 \mathrm{~h}$ opioid consumption and improves in-hospital rehabilitation but not post-discharge outcomes after total knee arthroplasty with peripheral nerve block. Br J Anaesth. 2014;113(5):855-64.

19. Lunn TH, Husted H, Laursen MB, Hansen LT, Kehlet H. Analgesic and sedative effects of perioperative gabapentin in total knee arthroplasty: a randomized, double-blind, placebo-controlled dose-finding study. Pain. 2015;156(12):2438-48.
20. Texas Tech University Health Sciences Center. Pain control with total knee replacement. In: ClinicalTrialsgov; 2012. Available from: https://clinicaltrials. gov/ct2/show/NCT01680549 Identifier: NCT01680549.

21. Vasta S, Papalia R, Torre G, Vorini F, Papalia G, Zampogna B, et al. The influence of preoperative physical activity on postoperative outcomes of knee and hip arthroplasty surgery in the elderly: a systematic review. J Clin Med. 2020;9(4):969.

22. Li XD, Han C, Yu WL. Is gabapentin effective and safe in open hysterectomy? A PRISMA compliant meta-analysis of randomized controlled trials. J Clin Anesth. 2017;41:76-83.

23. Han C, Kuang MJ, Ma JX, Ma XL. The efficacy of preoperative gabapentin in spinal surgery: a meta-analysis of randomized controlled trials. Pain Physician. 2017;20(7):649-61.

24. Jiang Y, Li J, Lin H, Huang Q, Wang T, Zhang S, et al. The efficacy of gabapentin in reducing pain intensity and morphine consumption after breast cancer surgery: a meta-analysis. Medicine (Baltimore). 2018;97(38): e11581.

25. Hah J, Mackey SC, Schmidt P, McCue R, Humphreys K, Trafton J, et al. Effect of perioperative gabapentin on postoperative pain resolution and opioid cessation in a mixed surgical cohort a randomized clinical trial. JAMA Surg. 2018;153(4):303-11.

26. Mishriky BM, Waldron NH, Habib AS. Impact of pregabalin on acute and persistent postoperative pain: a systematic review and meta-analysis. $\mathrm{Br} J$ Anaesth. 2015;114(1):10-31.

27. Erklıç E, Kesimci E, Sahin D, Bektaşer B, Yalçın N, Ellik S, et al. Does preemptive gabapentin modulate cytokine response in total knee arthroplasty? A placebo controlled study. Adv Clin Exp Med. 2018;27(4):487-91.

28. Felder L, Saccone G, Scuotto S, Monks DT, Carvalho JCA, Zullo F, et al. Perioperative gabapentin and post cesarean pain control: a systematic review and meta-analysis of randomized controlled trials. Eur J Obstet Gynecol Reprod Biol. 2019;233:98-106.

29. Kjaer Petersen $K$, Lunn TH, Husted H, Hansen LT, Simonsen O, Laursen MB, et al. The influence of pre- and perioperative administration of gabapentin on pain 3-4 years after total knee arthroplasty. Scand J Pain. 2018;18(2):237-45.

30. Hu J, Huang D, Li M, Wu C, Zhang J. Effects of a single dose of preoperative pregabalin and gabapentin for acute postoperative pain: a network metaanalysis of randomized controlled trials. J Pain Res. 2018;11:2633-43.

\section{Publisher's Note}

Springer Nature remains neutral with regard to jurisdictional claims in published maps and institutional affiliations.
Ready to submit your research? Choose BMC and benefit from:
- fast, convenient online submission
- thorough peer review by experienced researchers in your field
- rapid publication on acceptance
- support for research data, including large and complex data types
- gold Open Access which fosters wider collaboration and increased citations
- maximum visibility for your research: over $100 \mathrm{M}$ website views per year
At BMC, research is always in progress.
Learn more biomedcentral.com/submissions 